\title{
Stem cell-like circulating tumor cells indicate poor prognosis in gastric cancer
}

\author{
Wang Yi-Wen ${ }^{1}$, Li Long-Long ${ }^{1}$, Lu Ming ${ }^{1}$, Li Hao² ${ }^{2}$ Hu Kong-Wang ${ }^{1}$
}

${ }^{1}$ Department of Gastrointestinal Surgery, Department of General Surgery,
First Affiliated Hospital of Anhui Medical University, Anhui, China
${ }^{2}$ Department of Pathology, Affiliated Hospital of Anhui Medical University, Anhui, China

Submitted: 15 September 2018

Accepted: 3 May 2019

Arch Med Sci

DOI: https://doi.org/10.5114/aoms.2020.97707

Copyright $\odot 2020$ Termedia \& Banach

\section{Abstract}

Introduction: Circulating tumor cells (CTCS) have the characteristics of cancer stem cells and play an important role in the recurrence and metastasis of tumors. CD44 is a surface marker molecule for gastric cancer stem cells (GCSCS) and can be used to identify and isolate GCSCs. Here, we investigated the effect of CD44 protein expression, circulating tumor cells, and CD44-positive CTCs on the prognosis of gastric cancer (GC).

Material and methods: Blood samples from $58 \mathrm{GC}$ patients being treated at the First Affiliated Hospital of Anhui Medical University from August 2015 to October 2016 were obtained before surgery. The cancer tissues from 58 GC patients after surgery and the same amount of adjacent normal tissues $5 \mathrm{~cm}$ away from the center of the cancer tissues were collected as controls. Immunohistochemistry was used to detect CD44 expression in cancer tissues and adjacent normal tissues. Immunomagnetically negative enrichment combined with im-FISH was used to detect CTCs and CD44-positive CTCs in gastric cancer patients.

Results: Circulating tumor cells were detected in 44 of 58 patients, and CD44 protein was positive in 34 cases of GC. The presence of CTCS and CD44 is significantly associated with depth of tumor infiltration, lymph node metastasis, TNM stage, and recurrence $(p<0.01)$. Twenty-nine of 44 CTC-positive patients had CD44-positive CTCs. The patients with CD44-positive CTCs were more likely to develop recurrence than patients with CD44-negative CTCs $(p<0.01)$. Furthermore, 28 of 29 patients with CD44-positive CTCS developed recurrent disease, and the mean time to recurrence was shorter than that in patients with CD44-negative CTCs (16.030 \pm 5.268 and 21.800 \pm 4.601 months; $p<0.01$ ). The Cox proportional hazards model indicated that the presence of CD44-positive CTCS and TNM stage were independent predictors of recurrence for GC ( $p=0.044$ and 0.035).

Conclusions: The detection of stem cell characteristics of GC CTCS can provide more prognostic information than simply detecting GC CTCs and GC CD44 expression.

Key words: gastric cancer (GC), circulating tumor cells (CTCS), cancer stem cells (CSCs), CD44, immunofluorescence in situ hybridization (im-FISH), immunohistochemistry (IHC).

\section{Introduction}

Gastric cancer (GC) is the fourth most common cancer and second leading cause of cancer-related deaths in the world [1, 2]. New forms of diagnosis and treatment of gastric cancer continue to emerge, but

\author{
Corresponding author: \\ Prof. Hu Kong-Wang \\ Department of General Surgery \\ Department of Gastrointestinal \\ Surgery \\ The First Affiliated Hospital \\ of Anhui Medical University \\ 218 JiXi Avenue, Hefei 230022 \\ Anhui, PR China \\ E-mail: hukw@sina.com
}


the five-year relative survival rate is still low $[3,4]$, due to tumor recurrence and metastasis [5]. Malignant tumor cells will detach from the primary tumor foci and diffuse into the blood or lymph system through the circulatory system [6]. The tumor cells that enter the peripheral blood circulation are circulating tumor cells (CTCS) [7]. The current research on CTCs is in full swing $[8,9]$. Circulating tumor cells possess the phenotype and genetic information of primary tumor cells, and are probably related to the occurrence, development, treatment and prognosis of tumors, and can be used as a "liquid biopsy" for metastatic tumors [10,11]. Circulating tumor cells can be detected in the peripheral blood of patients with GC; these CTCS may lead to the recurrence and metastasis of GC [12]. However, not all tumor cells entering the peripheral circulation will lead to recurrence and metastasis. Just a population of CTCS with stem cell-like properties can survive and form metastases [13]. These cells are called circulating tumor stem cells (CTSCS) and have the characteristics of self-renewal, differentiation, and proliferation of CSCs [14]. These characteristics are precisely a key factor in the postoperative recurrence and metastasis of GC, so it is imperative to find the factors and sensitive monitoring indicators that cause postoperative recurrence of GC.

With the progress of technology, CTCS in GC can be detected and identified. The FDA-approved CellSearch system for metastatic breast cancer uses the expression of epithelial cell adhesion molecules (EPCAM) on the surface of tumor cells to isolate CTCS [15]. This method relies on the expression of tumor EpCAM and results in false negative results [16]. So we used an improved EpCAM-independent enrichment strategy followed by a new strategy that combines ICC CD45 staining with FISH (CD45-FISH) to increase the sensitivity and specificity of CTC detection. Studies have indicated that CTCS could predict poor prognosis of GC patients [17]. However, few studies have reported on CTSCs for the prognosis and biological relevance of GC patients. As we all know, CD44 is a stem cell-specific surface marker for GC [18]. CD44 is a special cell surface transmembrane glycoprotein belonging to the adhesion molecule, located on the short arm of human chromosome 11, with a CDNA length of about $50 \mathrm{~kb}$. It consists of 20 highly conserved exons and corresponding introns and can participate in specific adhesion between cells as well as between cells and matrix [19]. Sorting stem cells by specific characteristics of CD44 protein is beneficial to further study the biological characteristics, signaling pathways, and drug resistance mechanisms of cancer stem cells [20]. In this study, IHC was used to detect CD44 protein expression in GC patients, and im-
FISH was used to detect CTCs and CD44-positive CTCs in GC patients. An investigation into its value in clinical pathological parameters and prognosis of GC was conducted.

\section{Material and methods}

\section{Materials}

\section{Specimen source and clinical information}

Experimental group: 58 GC patients being treated at the First Affiliated Hospital of Anhui Medical University from August 2015 to October 2016. Control group: 25 healthy volunteers from Anhui Medical University First Affiliated Hospital Health Checkup Center. Clinical information: Detailed clinicopathological data, including gender, age, tumor size, T stage, TNM stage, and vascular invasion and lymph node metastasis, were collected through the hospital electronic case system for all of the patients.

\section{Tissue specimens}

The cancer tissues from 58 GC patients after surgery and the same amount of adjacent normal tissues $5 \mathrm{~cm}$ away from the center of the cancer tissues were collected as controls. All tissue specimens were fixed with $10 \%$ neutral formalin, routinely dehydrated, paraffin-embedded, and serially sectioned at $4 \mu \mathrm{m}$ thickness.

\section{Blood samples}

Blood samples from 58 GC patients being treated at the First Affiliated Hospital of Anhui Medical University from August 2015 to October 2016 were obtained before surgery. The patients did not suffer from other cancers, and were without radiation and chemotherapy treatment before surgery. Blood samples from 25 healthy volunteers served as controls. $5 \mathrm{ml}$ of blood was collected into ACD anti-coagulant tubes (Becton, Dickinson and Company, USA). After discarding the first $1 \mathrm{ml}$ of blood to avoid contamination of the blood sample with epithelial cells of skin they were then stored at $4^{\circ} \mathrm{C}$ less than 4 hours before the experiment.

\section{Follow-up information}

Telephone contact follow-up was performed once a month after surgery for all patients. We established whether the patient had recurrence and/or metastasis, and ultimately made a diagnosis based on CT or MRI, with or without histological confirmation. Patients with accidental death were excluded, and the follow-up for patients ended in February 2018. This study was approved by the Ethics Committee of the First Affiliated Hospital of Anhui Medical University. Informed 
consent was obtained from both GC patients and cancer-free volunteers before obtaining samples.

\section{Methods}

\section{Immunohistochemistry}

Tissue samples of gastric cancer were placed in an oven and fixed at a temperature of $58-60^{\circ} \mathrm{C}$. After $1 \mathrm{~h}$, samples were deparaffinized with xylene and dehydrated with ethanol. Endogenous peroxidase was removed with $3 \% \mathrm{H}_{2} \mathrm{O}_{2}$ at room temperature. The samples were then immersed in citric acid buffer and placed in a microwave oven for antigen retrieval. After repair, the samples were allowed to cool naturally. PBS was rinsed, and 5\% BSA was added dropwise. Blocking was performed for 20 min. After removing excess fluid, CD44 mouse monoclonal antibody (dilution 1 : 200, Beijing Anbiqi Bios, China) was added dropwise overnight at $4^{\circ} \mathrm{C}$. After washing with PBS, biotinylated goat antimouse IgG (1:100, Beijing Anbiqi Bios, China) was added dropwise and incubated at $37^{\circ} \mathrm{C}$ for $30 \mathrm{~min}$. After washing with PBS, Strept Avidin-Biotin Complex (SABC, secondary antibody kit, Beijing Anbiqi Bios, China) was added and incubated at $37^{\circ} \mathrm{C}$ for $30 \mathrm{~min}$. After the end of the reaction, samples were washed again with PBS, then DAB was added for color development and to control the reaction time under a microscope. At the end of staining, distilled water was added in order to stop the color development. Hematoxylin was dehydrated and sealed after mild counterstaining. The positive control was a known standard positive slice provided by the reagent company, while PBS instead of the primary antibody was a negative control. Two pathologists performed double-blind reading and scored independently. The cell membrane or cytoplasm staining of CD44-positive protein was brownish yellow. Two senior pathologists performed scoring and analysis according to the staining intensity and the percentage of stained cells. The results were judged using the uniform scoring standard and double-blind method. Dyeing intensity: 0 points without coloring, 1 point with light yellow, 2 points with brown and 3 points with tan. The percentage of colored cells in the total cell count was scored as follows: less than $5 \%$ for 0 points, $5 \%$ to $25 \%$ for 1 point, $25 \%$ to $50 \%$ for 2 points, $50 \%$ to $75 \%$ for 3 points, and $>75 \%$ for 4 points. In the low power microscope, 10 visual fields were randomly observed for each slice. The obtained results were averaged, and the staining intensity was multiplied by the percentage of stained cells. Final score $\leq 3$ is negative, $>3$ is positive.

\section{Im FISH}

1. Blood density gradient centrifugation and cell pretreatment. We transferred $5 \mathrm{ml}$ of blood to a $50 \mathrm{ml}$ centrifuge tube and diluted to $45 \mathrm{ml}$ with $1 \times$ PBS. After centrifugation at $400 \times \mathrm{g}$ for $5 \mathrm{~min}$ at room temperature, we removed the supernatant. The Erythrocyte Lysis Solution (Leagene, Beijing, China) was added to the supernatant to $45 \mathrm{ml}$ and incubated at room temperature for $8 \mathrm{~min}$. After centrifugation at $400 \mathrm{~g}$ for $5 \mathrm{~min}$, supernatant was removed, and lysis was repeated once. PBS was added to $45 \mathrm{ml}$, cells were then re-suspended and counted. Cell pellets were re-suspended in PBS, followed by the addition of anti-CD45 antibody conjugated immune-magnetic beads (Miltenyi Biotec $\mathrm{GmbH}$, Germany) following a $10^{8}$ white blood cells (WBCs)/20 $\mu \mathrm{l}$ magnetic beads ratio. They were then incubated for $15 \mathrm{~min}$ at $4^{\circ} \mathrm{C}$; the suspension was then added to the LS column (Miltenyi Biotec $\mathrm{GmbH}$, Germany), and WBCs bound to beads were separated by means of a magnetic stand (Miltenyi Biotec $\mathrm{GmbH}$, Germany). We washed the LS column with $3 \mathrm{ml}$ of wash solution (Miltenyi Biotec $\mathrm{GmbH}$, Germany) three times, then collected the downflow solution. After centrifugation at $400 \times \mathrm{g}$ for $5 \mathrm{~min}$, the supernatant was removed to $0.1 \mathrm{ml}$. $15 \mathrm{ml}$ of A (1: 1 mixture of $0.4 \%$ potassium chloride solution and sodium citrate solution) was added, and bathed in $37^{\circ} \mathrm{C}$ after $20 \mathrm{~min} .0 .1 \mathrm{ml}$ of freshly prepared $\mathrm{B}(3: 1$ mixture of methanol and glacial acetic acid) was added next, then supernatant was removed to $0.1 \mathrm{ml}$ after centrifugation at $1000 \times \mathrm{g}$ for $5 \mathrm{~min}$, adding $5 \mathrm{ml}$ of $\mathrm{B}$ to place on ice for $20 \mathrm{~min}$. We removed the supernatant to $0.1 \mathrm{ml}$ after centrifugation at $3000 \times \mathrm{g}$ for $5 \mathrm{~min}$. $5 \mathrm{ml}$ of $\mathrm{B}$ was added to the centrifuge twice, the supernatant was removed to $0.1 \mathrm{ml}$ and the cell suspension was finally added to a clean slide. The cells were stored in absolute ethanol at $-20^{\circ} \mathrm{C}$ before use after overnight storage at $56^{\circ} \mathrm{C}$.

2. Probe hybridization. Slides were soaked in pretreatment solution (2XSSC $+0.5 \%$ NP-40) at $37^{\circ} \mathrm{C}$ for $30 \mathrm{~min}$, and dehydrated in $70 \%, 90 \%$, and $100 \%$ ethanol for 1 min each. Gradient dehydration was performed in $70 \%, 90 \%, 100 \%$ ethanol for 1 min after denaturation at $73^{\circ} \mathrm{C}(70 \%$ formamide +1 XSSC) for 5 min. Vysis Spectrum Orange labeled centromere probe 8 (CEP8, GeneCopoeia) was added to slides avoiding light according to the manufacturer's instructions. Slides were denatured at $80^{\circ} \mathrm{C}$ for 5 minutes and incubated in a preheated humidor at $42^{\circ} \mathrm{C}$ for $16-24$ hours.

3. Double immunofluorescent staining to detect CD45 and CD44 in dark conditions. Slides were washed in $73^{\circ} \mathrm{C}$ wash solution $(0.5$ XSSC + $0.1 \% \mathrm{NP}-40$ ) for $5 \mathrm{~min}$. Cells were permeabilized with $0.1 \%$ TritonX-100-PBS for $10 \mathrm{~min}$, washed three times with PBS, and blocked with $2 \%$ BSAPBS for $30 \mathrm{~min}$ at room temperature. They were then incubated with CD44 mouse monoclonal 
antibody (dilution $1: 100$, China) at $37^{\circ} \mathrm{C}$ for $1 \mathrm{~h}$ and washed for 10 min with blocking buffer $(5 \%$ BSA), then the samples were incubated with FITC conjugated rabbit anti-human IgG (dilution 1 : 100, China) and Alexa Fluor 594 conjugated anti-human CD45 (1 : 100), at room temperature for $1 \mathrm{~h}$, followed by washing and mounting the slides. In the control group PBS was added instead of antibody for the experiment. Slides were mounted with DAPI. The slides were observed with an Olympus-BX53 fluorescence microscope (OLYMPUS, Japan). CTCS were identified as CEP8+/DAPI+/CD45-. CD44-positive CTCs were identified as CEP8+/DAPI+/CD45-/CD44+. CEP8+ was defined as more than two red CEP8 signals in nuclei of each cell. The distance between two signals with less than one signal diameter is considered as a split and enumerated as one signal. Overlapping, aggregating, or smearing cells were excluded. Less than $2 \%$ of cells with no CEP8 signal are considered as acceptable hybridization efficiency according to the manufacturer's instructions. DAPI+ was defined as blue nuclei. CD44+ was defined as green cells. CD45+ was defined as red cell membrane. The number of CTCs per slide and the number of corresponding CD44-positive CTCS were counted, and the count was repeated five times to obtain the final value. The human gastric cancer cell line BGC-823 was obtained from the Hefei Cancer Research Institute. To determine assay sensitivity, 10 BGC-823 cells were added to $5 \mathrm{ml}$ of blood from healthy volunteers prior to being processed as described above for patient samples.

\section{Statistical analysis}

Statistical analysis was conducted using the SPSS 21.0 software. Data are expressed either as mean \pm standard deviation or as percentages. The $D c^{2}$ test, Fisher test, and Student's $t$-test were used to establish significance. Two-tailed $p<0.05$ values were considered statistically significant. Kaplan-Meier survival analysis and logrank test were performed to analyze the time to recurrence for the CD44, CTCS and CD44-positive CTCS groups. Multivariate recurrence analysis was performed using the COX proportional hazards model. All statistical tests were two-sided.

\section{Results}

\section{Patient characteristics}

58 GC patients, comprising 38 males and $20 \mathrm{fe}$ males, with a mean age of $62.09 \pm 12.284$ years, were included in the present study. The time to recurrence ranged from 8 to 30 months (mean $20.50 \pm 6.827$ months). Of the 58 patients, 30 had TNM stage I/II and 28 had TNM stage III/IV.

\section{Immunohistochemical expression of CD44 in cancer tissue and adjacent normal tissues}

CD44 obviously expressed in cell membrane and cytoplasm in GC. Positive and negative CD44 expression in cancer tissue and adjacent normal tissues (Figure 1).

\section{Definition of circulating tumor cells, CD44-positive circulating tumor cells in gastric cancer patients}

CTCs were identified as CEP8+/DAPI+/CD45(Figure 2), CD44-positive CTCS were identified as CEP8+/DAPI+/CD45-/CD44+ (Figure 2); CD44negative CTCS were identified as CEP8+/DAPI+/ CD45-/CD44- (Figure 3). No CTCs were detected in the control group. 10 BGC-823 human gastric cancer cells in $5 \mathrm{ml}$ of blood were obtained from healthy volunteers. In these spike-recovery experiments, the recovery rate of BCG-823 cells was approximately between $90 \%$ and $95 \%$.

\section{Relation between circulating tumor cells, CD44 and clinical pathological data of gastric cancer patients}

Detailed clinical pathological data and CTC and CD44 status in the GC patients included in this study are summarized in Table I. The presence of CTCS and CD44 was significantly associated with T stage, lymph node metastasis, TNM stage, differentiation and recurrence of GC $(p<0.05)$. Of the 58 GC patients analyzed, 44 (75.86\%) and 34 (58.62\%) were identified as CTC-positive and CD44-positive. Both are significantly higher than the control group $(p<0.05)$. Among the 44 CTC-positive patients, 38 patients $(86.36 \%)$ and 30 patients $(68.18 \%)$ developed lymph node metastasis and recurrence, respectively. Among the 34 CD44-positive patients, 31 patients (91.17\%) and 27 patients $(79.41 \%)$ developed lymph node metastasis and recurrence, respectively. No statistically significant difference was detected between the CTC-positive patients, CD44-postive patients and the CTC-negative patients, CD44-negative patients with respect to age, gender, tumor size, vascular invasion, and histologic grade, respectively $(p>0.05$, Table I).

\section{Relation between CD44-positive circulating tumor cells and clinical pathological data of gastric cancer patients}

Clinical pathological data and CD44-positive CTC status in the GC patients included in this study are summarized in Table II. The incidence of CD44-positive CTCs was significantly associated with tumor location, lymph node metas- 

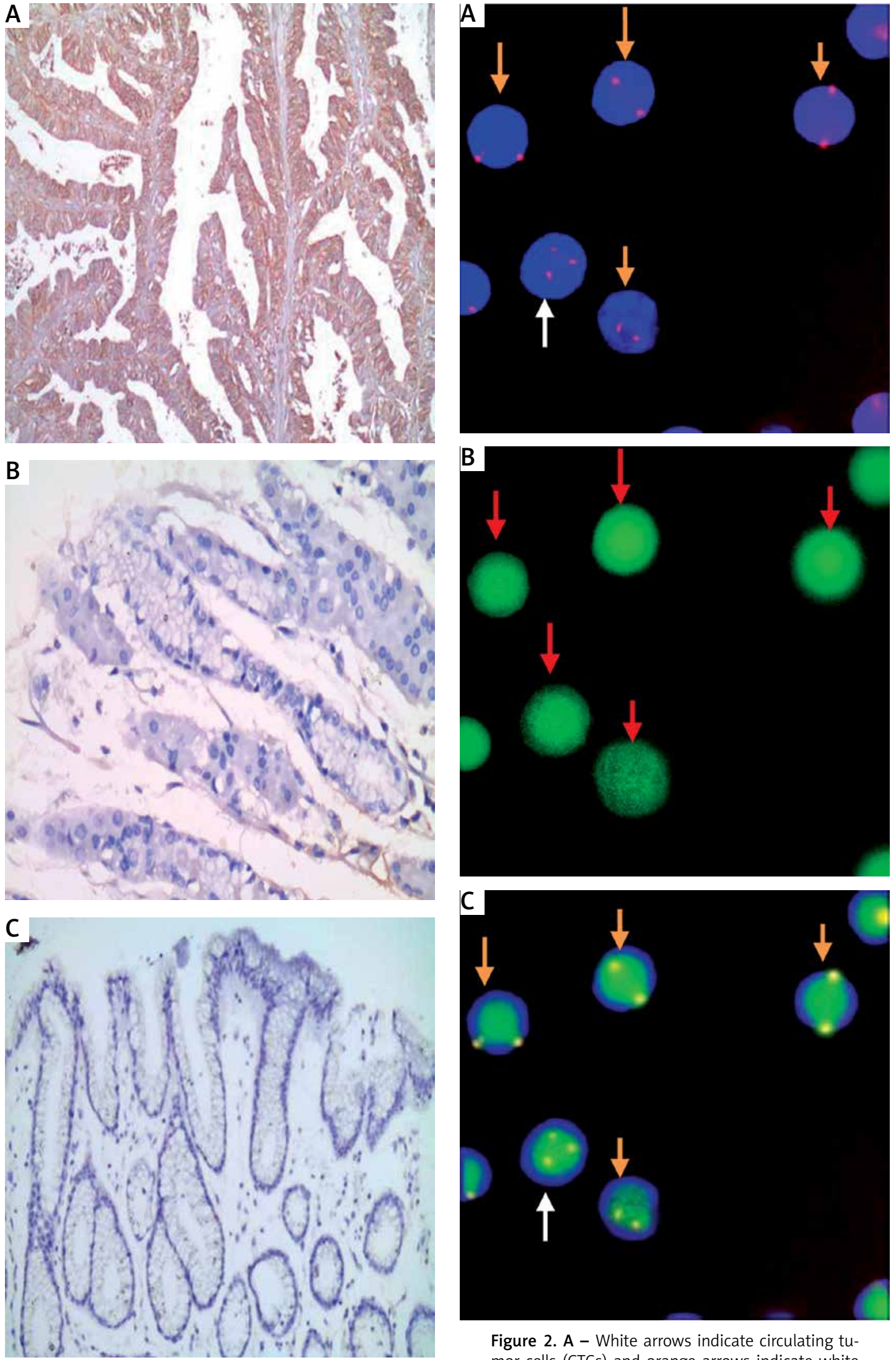

Figure 2. A - White arrows indicate circulating tumor cells (CTCS) and orange arrows indicate white blood cells. B - Green cells indicated by red arrows are CD44 positive. $\mathrm{C}-$ White arrow indicates CD44-positive CTCs and orange arrows indicate

cer (GC) tissue ( $\times 200)$. B - Negative CD44 expression in GC tissue $(\times 400)$. C - Negative CD44 expression in normal tissue adjacent to cancer $(\times 200)$
WBCs combining with $\mathbf{A}$ and $\mathbf{B}$. Magn. $\times 100$ 

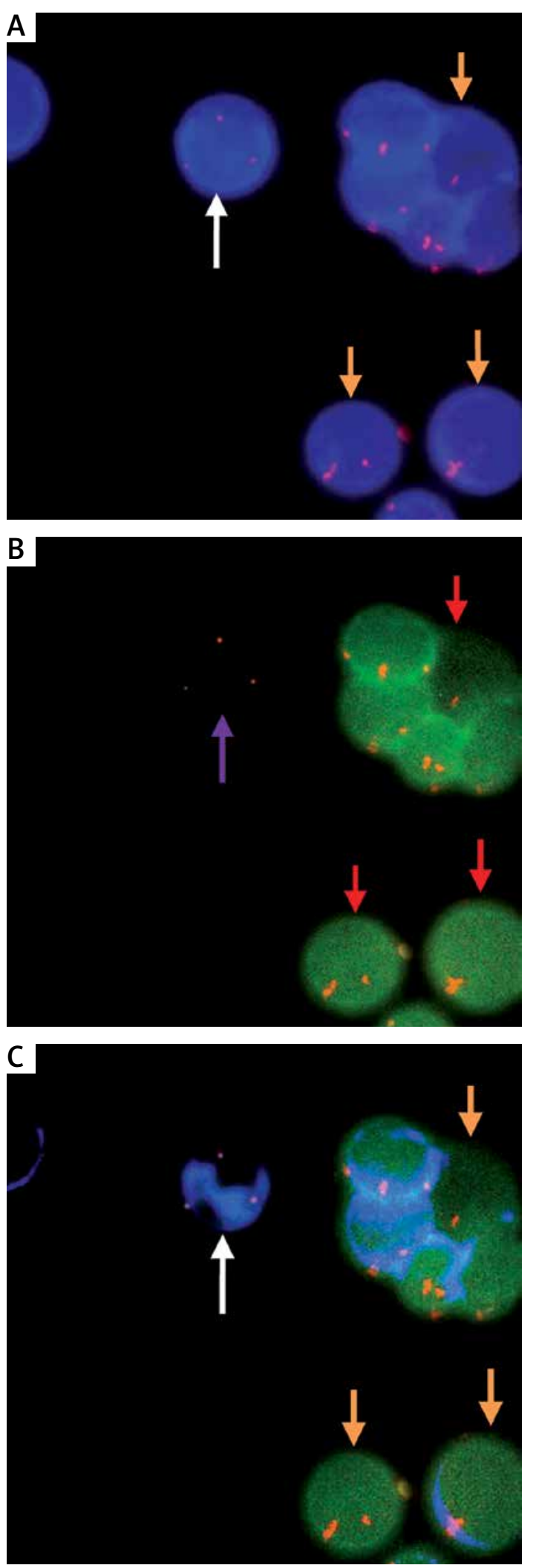

Figure 3. A - White arrows indicate circulating tumor cells (CTCS) and orange arrows indicate white blood cells (WBCs). B - Purple arrow indicates CD44-negative and red arrow indicates CD44-positive cells. C - White arrows indicate CD44-negative CTCs and orange arrows indicate WBCs combining with A and B. Magn. $\times 100$

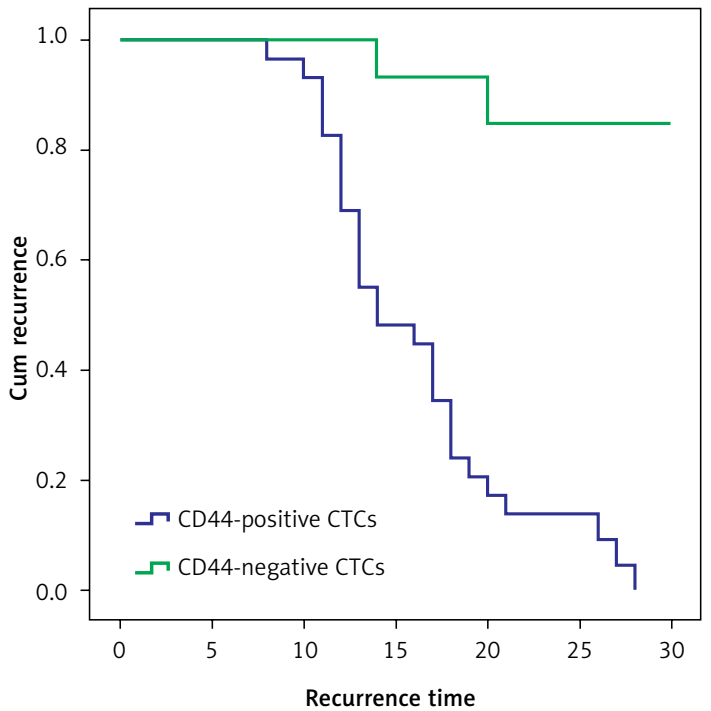

Figure 4. The recurrent time of CD44-positive circulating tumor cells (CTCs) group was shorter than that of CD44-negative CTCs group $(p<0.01)$ (28 of the 29 patients with CD44-positive CTCs had recurrence; 2 of the 15 patients with CD44-negative CTCs group had recurrence; the mean time to recurrence was shorter than that in patients with CD44-negative CTCs [16.030 \pm 5.268 and $21.800 \pm 4.601$ months; $\left.\left.\chi^{2}=22.978, p<0.01\right]\right)$

tasis, distant metastasis, and recurrence of GC $(p<0.001)$. CD44-positive CTCs were detected in $29(65.91 \%)$ of the 44 CTC-positive patients. Among the 29 patients with CD44-positive CTCs, all patients and 28 patients (96.55\%) developed lymph node and recurrence, respectively. The number of CD44-positive CTCS was significantly higher in patients with recurrent disease than in disease-free patients (mean number of CD44-positive CTC 2.31 and 0; resp; $p<0.05$ ).

Cox proportional hazards model analysis of clinical data of 58 patients with gastric cancer

Univariate analysis of Cox proportional hazard model was performed and showed that tumor size, depth of infiltration, lymph node metastasis, TNM stage, CD44, CTC, and CD44-CTC were prognostic factors of gastric cancer ( $p<0.05$, Table III). Multi-factor analysis of the Cox proportional hazard model showed that the presence of CD44-positive CTCS and the TNM stage were independent indicators of recurrence for GC $(p=0.044$ and 0.035, Table IV).

Analysis of CD44-positive circulating tumor cells and CD44-negative circulating tumor cells with gastric cancer recurrence

Twenty-eight of 29 patients with CD44-positive CTCs developed recurrent disease, and the mean time to recurrence was shorter than that in pa- 
Table I. Relationship between circulating tumor cells (CTCS), CD44 and clinical pathological data of gastric cancer patients

\begin{tabular}{|c|c|c|c|c|c|c|c|c|c|}
\hline \multirow[t]{2}{*}{ Characteristic } & \multirow[t]{2}{*}{$n$} & \multicolumn{4}{|c|}{ CTCs } & \multicolumn{4}{|c|}{ CD44 } \\
\hline & & Positive & Negative & $\chi^{2}$ & $P$ & Positive & negative & $\chi^{2}$ & $P$ \\
\hline \multicolumn{10}{|l|}{ Gender } \\
\hline Male & 38 & 29 & 9 & 0.012 & 0.911 & 20 & 18 & 1.630 & 0.202 \\
\hline Female & 20 & 15 & 5 & & & 14 & 6 & & \\
\hline \multicolumn{10}{|l|}{ Age (years) } \\
\hline$\geq 60$ & 47 & 36 & 11 & 0.073 & 0.787 & 26 & 21 & 1.114 & 0.291 \\
\hline$<60$ & 11 & 8 & 3 & & & 8 & 3 & & \\
\hline \multicolumn{10}{|l|}{ Tumor size $(\mathrm{cm})$} \\
\hline$\geq 5$ & 22 & 20 & 2 & 3.159 & 0.076 & 15 & 7 & 1.336 & 0.248 \\
\hline$<5$ & 36 & 24 & 12 & & & 19 & 17 & & \\
\hline \multicolumn{10}{|l|}{ Vascular invasion } \\
\hline Positive & 12 & 11 & 1 & 2.064 & 0.151 & 8 & 4 & 0.404 & 0.525 \\
\hline Negative & 46 & 33 & 13 & & & 26 & 20 & & \\
\hline \multicolumn{10}{|l|}{ Histologic grade } \\
\hline Well differentiated & 6 & 3 & 3 & 2.444 & 0.118 & 2 & 4 & 1.764 & 0.184 \\
\hline Poorly differentiated & 52 & 41 & 11 & & & 32 & 20 & & \\
\hline \multicolumn{10}{|l|}{ T stage } \\
\hline $\mathrm{T} 1-2$ & 14 & 6 & 8 & 10.978 & 0.001 & 2 & 12 & 14.954 & $<0.001$ \\
\hline T3-4 & 44 & 38 & 6 & & & 32 & 12 & & \\
\hline \multicolumn{10}{|l|}{ Lymph node metastasis } \\
\hline Positive & 39 & 38 & 1 & 30.202 & $<0.001$ & 31 & 8 & 21.370 & $<0.001$ \\
\hline Negative & 19 & 6 & 13 & & & 3 & 16 & & \\
\hline \multicolumn{10}{|l|}{ TNM stage } \\
\hline$|-| \mid$ & 30 & 17 & 13 & 12.504 & $<0.001$ & 9 & 21 & 20.985 & $<0.001$ \\
\hline III-IV & 28 & 27 & 1 & & & 25 & 3 & & \\
\hline \multicolumn{10}{|l|}{ Recurrence } \\
\hline Positive & 30 & 30 & 0 & 19.773 & $<0.001$ & 27 & 3 & 25.226 & $<0.001$ \\
\hline Negative & 28 & 14 & 14 & & & 7 & 21 & & \\
\hline
\end{tabular}

tients with CD44-negative CTCs (16.030 \pm 5.268 and $21.800 \pm 4.601$ months; $p<0.01$, Figure 4).

\section{Discussion}

Circulating tumor cells are currently the focus of biological research [21]. With the continuous improvement of detection technology, CTC detection has gradually become a novel non-invasive detection method [22]. It is becoming more common in the early diagnosis of malignant tumors, monitoring of recurrence, therapeutic efficacy and prognosis evaluation. Studies have shown that
CTCs are an important cause of postoperative recurrence and distant metastasis in malignant tumor patients $[17,23]$. The traditional CTC detection method relies on the expression of EpCAM. However, CTCs express high vimentin and low expression of EpCAM through EMT [24]. Therefore, it is difficult to capture mesenchymal altered tumor cells through epithelial adhesion molecules, causing false negative results.

Persistent stem cell-like CTCs in peripheral blood cause poor prognosis of GC [25]. The CD44 molecule is a specific marker molecule for GCSCs and can be used to detect and isolate GCSCs [26, 27]. 
Table II. Relationship between CD44-positive circulating tumor cells (CTCS) and clinical pathological data of gastric cancer patients

\begin{tabular}{|c|c|c|c|c|c|}
\hline \multirow[t]{2}{*}{ Characteristic } & \multirow[t]{2}{*}{$n$} & \multicolumn{4}{|c|}{ CD44-positive CTCs } \\
\hline & & Positive & Negative & $\chi^{2}$ & $P$ \\
\hline \multicolumn{6}{|l|}{ Gender } \\
\hline Male & 34 & 20 & 14 & 3.343 & 0.068 \\
\hline Female & 10 & 9 & 1 & & \\
\hline \multicolumn{6}{|l|}{ Age (years) } \\
\hline$\geq 60$ & 36 & 23 & 13 & 0.360 & 0.549 \\
\hline$<60$ & 8 & 6 & 2 & & \\
\hline \multicolumn{6}{|l|}{ Tumor size $(\mathrm{cm})$} \\
\hline$\geq 5$ & 24 & 14 & 10 & 1.349 & 0.246 \\
\hline$<5$ & 20 & 15 & 5 & & \\
\hline \multicolumn{6}{|l|}{ Vascular invasion } \\
\hline Positive & 33 & 20 & 13 & 1.652 & 0.199 \\
\hline Negative & 11 & 9 & 2 & & \\
\hline \multicolumn{6}{|l|}{ Histologic grade } \\
\hline Well-differentiated & 3 & 2 & 1 & 0.001 & 0.977 \\
\hline Poorly differentiated & 41 & 27 & 14 & & \\
\hline \multicolumn{6}{|l|}{ T stage } \\
\hline T1-2 & 6 & 2 & 4 & 3.281 & 0.070 \\
\hline T3-4 & 38 & 27 & 11 & & \\
\hline \multicolumn{6}{|l|}{ Lymph node metastasis } \\
\hline Positive & 38 & 29 & 9 & 13.432 & 0.001 \\
\hline Negative & 6 & 0 & 6 & & \\
\hline \multicolumn{6}{|l|}{ TNM stage } \\
\hline$|-| \mid$ & 17 & 6 & 11 & 11.556 & $<0.001$ \\
\hline III-IV & 27 & 23 & 4 & & \\
\hline \multicolumn{6}{|l|}{ Recurrence } \\
\hline Positive & 30 & 28 & 2 & 31.560 & $<0.001$ \\
\hline Negative & 14 & 1 & 13 & & \\
\hline
\end{tabular}

In this study, we detected the expression of the GCSC marker CD44 in gastric cancer tissues and adjacent normal tissues. Statistical analysis showed that the expression of CD44 in gastric cancer tissues was significantly higher than that in adjacent normal tissues $(p<0.05)$. At the same time, we found that CD44 was associated with invasive depth, lymph node metastasis, TNM stage, and postoperative recurrence of gastric cancer $(p<0.05)$, which agreed with the studies of some other researchers $[28,29]$. The results indicated that CD44 may mediate tumor metastasis. Sub- sequently, immunomagnetically negative enrichment combined with im-FISH was used to detect CTCS and CD44-positive CTCS in gastric cancer patients. Circulating tumor cells were detected in 44 cases in $58 \mathrm{GC}$ patients. This negative enrichment instead of EpCAM expression detected CTCs and reduced false negative results compared with positive enrichment detection. The spike-recovery experiments of BCG-823 cells confirmed the sensitivity and specificity of the method. Circulating tumor cells were associated with tumor invasive depth, lymph node metastasis, TNM stage, and 
Table III. Univariate analysis of Cox proportional hazard model in 58 gastric cancer patients

\begin{tabular}{|c|c|c|c|c|c|c|c|c|}
\hline \multirow[t]{2}{*}{ Factor } & \multirow[t]{2}{*}{ B } & \multirow[t]{2}{*}{ SE } & \multirow[t]{2}{*}{ Wald } & \multirow[t]{2}{*}{ df } & \multirow[t]{2}{*}{ Sig. } & \multirow[t]{2}{*}{$\operatorname{Exp}(B)$} & \multicolumn{2}{|c|}{$95 \% \mathrm{Cl}$ for $\operatorname{Exp}(\mathrm{B})$} \\
\hline & & & & & & & Lower & Upper \\
\hline Gender (male/female) & 0.411 & 0.369 & 1.240 & 1 & 0.265 & 1.509 & 0.732 & 3.112 \\
\hline Age/years $(\leq 60 />60)$ & 0.019 & 0.457 & 0.002 & 1 & 0.967 & 1.019 & 0.416 & 2.495 \\
\hline Tumor size $(<5 / \geq 5) \mathrm{cm}$ & 0.927 & 0.369 & 6.297 & 1 & 0.012 & 2.526 & 1.225 & 5.208 \\
\hline Vascular invasion (positive/negative) & 0.435 & 0.414 & 1.104 & 1 & 0.293 & 1.545 & 0.686 & 3.476 \\
\hline Histologic grade (well/poorly) & 0.762 & 0.734 & 1.077 & 1 & 0.299 & 2.143 & 0.508 & 9.037 \\
\hline Depth of infiltration (T1-2/T3-4) & 1.973 & 0.738 & 7.153 & 1 & 0.007 & 7.195 & 1.694 & 30.556 \\
\hline Lymph node metastasis (positive/negative) & 4.648 & 1.531 & 9.218 & 1 & 0.002 & 104.410 & 5.195 & 2098.607 \\
\hline TNM stage $(|-||/|||-\mid \mathrm{V})$ & 2.894 & 0.531 & 29.695 & 1 & 0.000 & 18.058 & 6.378 & 51.129 \\
\hline CD44 (positive/negative) & -2.539 & 0.619 & 16.825 & 1 & 0.000 & 0.079 & 0.023 & 0.266 \\
\hline CTC (positive/negative) & -3.964 & 1.617 & 6.010 & 1 & 0.000 & 0.014 & 0.001 & 0.452 \\
\hline CD44-CTC (positive/negative) & -3.562 & 0.748 & 22.686 & 1 & 0.000 & 0.028 & 0.007 & 0.123 \\
\hline
\end{tabular}

Table IV. Multivariate analysis of Cox proportional hazard model in 58 gastric cancer patients

\begin{tabular}{|lcccccccc|}
\hline Factor & B & SE & Wald & df & Sig. & Exp(B) & \multicolumn{2}{c|}{$95 \%$ Cl for $\operatorname{Exp}(B)$} \\
\hline Tumor size $(<5 / \geq 5) \mathrm{cm}$ & 0.260 & 0.437 & 0.354 & 1 & 0.552 & 1.297 & 0.550 & 3.057 \\
\hline Depth of infiltration (T1-2/T3-4) & -0.862 & 0.974 & 0.783 & 1 & 0.376 & 0.422 & 0.063 & 2.849 \\
\hline $\begin{array}{l}\text { Lymph node metastasis } \\
\text { (positive/negative) }\end{array}$ & 10.446 & 152.874 & 0.005 & 1 & 0.946 & 34420.443 & 0.000 & $4.610 \mathrm{E}+134$ \\
\hline TNM classification (I-II/III-IV) & 1.486 & 0.719 & 4.269 & 1 & 0.039 & 4.417 & 1.079 & 18.079 \\
\hline CD44 (positive/negative) & -0.157 & 0.675 & 0.054 & 1 & 0.816 & 0.855 & 0.228 & 3.208 \\
\hline CTC (positive/negative) & -9.232 & 164.183 & 0.003 & 1 & 0.955 & 0.000 & 0.000 & $5.532 \mathrm{E}+135$ \\
\hline CD44-CTC (positive/negative) & -1.589 & 0.790 & 4.042 & 1 & 0.044 & 0.204 & 0.043 & 0.901 \\
\hline
\end{tabular}

postoperative recurrence of GC $(p<0.05)$, which was consistent with most of the findings [17, 22, 23]. In addition, there were 29 cases of CTC patients with positive CD44 expression. CD44-positive CTCs were associated with lymph node metastasis, TNM stage, and postoperative recurrence of gastric cancer $(p<0.05)$. Among them, 28 cases had recurrence, and the time of recurrence of CD44-positive CTC was shorter than that of CD44-negative CTCS (16.030 \pm 5.268 and $21.800 \pm 4.601$ months; $p<0.01)$. The Cox proportional hazards model indicated that the presence of CD44-positive CTCS and TNM stage were independent predictors of recurrence for GC. The study found that GC CTCS expressed CD44, and these cells were significantly associated with the prognosis of GC. It is probable that CD44-positive CTCs have the characteristics of gastric cancer stem cells (GCSCs), which mediate EMT and lead to the recurrence of tumor metastasis. As other studies show, Park et al. [30] revealed that CD44 can maintain the CSC characteristics of GC by regulating c-Myc transcription. It is suggested that CD44 -positive CTCS may have a poor prognosis by regulating and maintaining the characteristics of GCSCs. At the same time, Wei et al. [31] showed that RASSF10 could improve the prognosis of gastric cancer by regulating the decrease of CD44 expression via the Wnt/ $\beta$-catenin signaling pathway. It may be suggested that CD44 expression in CTCS modulates the Wnt/ $\beta$-catenin signaling pathway and causes the increase of RASSF10, which causes the recurrence and metastasis of GC. Xu et al. [32] showed that $\mathrm{CD} 44$ can regulate the $\mathrm{SHH}$ signaling pathway and increase the expression of the oncogene GLI1 related to the poor prognosis of GC. Wei et al. [33] showed that stress-related hormone Isopropenol regulated the increase of CD44 protein in GC through the beta2-AR/STAT3/miR-373 signal, leading to poor prognosis of GC. It may in- 
dicate that some CTC CD44 over-expression causes poor prognosis due to long-term psychological pressure in GC. Bates et al. [34] observed that CD44 produced activation of the src-family tyrosine kinase lyn. Moreover, overexpression of dominant-active lyn recapitulated chemoresistance via a pathway shown to involve activation of phosphoinositide 3-kinase/Akt. Chiappini et al. [35] found that phosphatidylinositol 3-kinase/AKT signaling pathway activation causes poor prognosis in GC. The finding indicates that CD44-positive CTC may cause poor prognosis of gastric cancer through activating phosphoinositide 3-kinase/ Akt. All of the above studies could explain the poor prognosis of CD44-positive CTC in GC patients, but the specific mechanism needs further study.

Of course, this study has some defects. The sample included in the studies is not large enough. In this study, circulating tumor cells and CD44-positive CTC assays have a long span of experimental steps. Incoherent experimental steps and cell counting methods under an artificial microscope possibly cause errors. At the same time, CTCs will naturally become apoptotic after isolation [34]. The blood preservation time needs to be as short as possible to reduce the natural apoptosis of CTCS and increase the detection rate. Besides, CD44 is expressed not only in gastric cancer CTCs but also in WBCs simultaneously. It is important to identify additional markers that may further narrow and define GCSCs in the future. This trial explored the end point of clinical follow-up for the recurrence of gastric cancer rather than the end of clinical death. We are still doing further follow-up, and we will further study the relationship between CD44-positive CTCS and the overall survival rate of patients with GC in the future. Another non-negligible defect, is that our methods just detect CTCS and CD44-positive CTCS instead of extracting and preserving for subsequent in vitro culture experiments such as tumorigenesis and chemotherapeutic drug efficacy testing.

In conclusion, CD44-positive CTCS may have certain characteristics of GCSCs, which causes poor prognosis of GC and is an effective monitoring indicator of GC prognosis.

\section{Acknowledgements}

We thank Lu Ming and Li Long-Long for their clinical data preparation. We also thank Li Hao for help with technical assistance.

This work was supported by Anhui Natural Science Fund Project (KJ20160323) and Provincial Quality Project of Anhui Province (2016jxtd061).

\section{Conflict of interest}

The authors declare no conflict of interest.

\section{References}

1. Siegel RL, Miller KD. Cancer statistics, 2018. CA Cancer J Clin 2018; 68: 7-30.

2. Ang TL, Fock KM. Clinical epidemiology of gastric cancer. Singapore Med J 2014; 55: 621-8.

3. Lazăr DC, Tăban S, Cornianu M, et al. New advances in targeted gastric cancer treatment. World J Gastroenterol 2016; 22: 6776-99.

4. Mihmanli M, Ilhan E, Idiz UO, et al. Recent developments and innovations in gastric cancer. World J Gastroenterol 2016; 22: 4307-20.

5. Wu X, Tao P, Zhou Q, et al. IL-6 secreted by cancer-associated fibroblasts promotes epithelial-mesenchymal transition and metastasis of gastric cancer via JAK2/STAT3 signaling pathway. Oncotarget 2017; 8: 20741-50.

6. Stuelten CH, Parent CA, Montell DJ, et al. Cell motility in cancer invasion and metastasis: insights from simple model organisms. Nat Rev Cancer 2018; 18: 296-312.

7. Bardelli A, Pantel K. Liquid biopsies, what we do not know (yet). Cancer Cell 2017; 31: 172-9.

8. Freitas VM, Hilfenhaus G. Metastasis of circulating tumor cells: speed matters. Dev Cell 2018; 45: 3-5.

9. Yao N, Jan YJ, Cheng S, et al. Structure and function analysis in circulating tumor cells: using nanotechnology to study nuclear size in prostate cancer. Am J Clin Exp Urol 2018; 6: 43-54.

10. Kaigorodova EV, Savelieva OE, Tashireva LA, et al. Heterogeneity of circulating tumor cells in neoadjuvant chemotherapy of breast cancer. Molecules 2018; 23: 727.

11. Babayan A, Pantel K. Advances in liquid biopsy approaches for early detection and monitoring of cancer. Genome Med 2018; 10: 21.

12. Abbaszadegan MR, Bagheri V, Razavi MS, et al. Isolation, identification, and characterization of cancer stem cells: a review. J Cell Physiol 2017; 232: 2008-18.

13. Schölch S, García SA, Iwata N, et al. Circulating tumor cells exhibit stem cell characteristics in an orthotopic mouse model of colorectal cancer. Oncotarget 2016; 7 : 27232-42.

14. Tinhofer I, Saki M, Niehr F, et al. Cancer stem cell characteristics of circulating tumor cells. Int J Radiat Biol 2014; 90: 622-7.

15. Neumann MH, Schneck H, Decker Y, et al. Isolation and characterization of circulating tumor cells using a novel workflow combining the CellSearchsystem and the CellCelector. Biotechnol Prog 2017; 33: 125-32.

16. Ning $\mathrm{N}$, Zhan T, Zhang Y, et al. Improvement of specific detection of circulating tumor cells using combined CD45 staining and fluorescence in situ hybridization. Clin Chim Acta 2014; 433: 69-75.

17. Yang C, Zou K, Yuan Z, et al. Prognostic value of circulating tumor cells detected with the CellSearch System in patients with gastric cancer: evidence from a meta-analysis. Onco Targets Ther 2018; 11: 1013-23.

18. Xia P, Xu XY. Prognostic significance of CD44 in human colon cancer and gastric cancer: evidence from bioinformatic analyses. Oncotarget 2016; 7: 45538-46.

19. Chen W, Zhang X, Chu C, et al. Identification of CD44+ cancer stem cells in human gastric cancer. Hepatogastroenterology 2013; 60: 949-54.

20. Nguyen PH, Giraud J, Chambonnier L, et al. Characterization of biomarkers of tumorigenic and chemoresistant cancer stem cells in human gastric carcinoma. Clin Cancer Res 2017; 23: 1586-97.

21. Wu CP, Wu P, Zhao HF, et al. Clinical applications of and challenges in single-cell analysis of circulating tumor cells. DNA Cell Biol 2018; 37: 78-89. 
22. Zamay AS, Zamay GS, Kolovskaya OS, et al. Aptamerbased methods for detection of circulating tumor cells and their potential for personalized diagnostics. Adv Exp Med Biol 2017; 994: 67-81.

23. Kang HM, Kim GH, Jeon HK, et al. Circulating tumor cells detected by lab-on-a-disc: role in early diagnosis of gastric cancer. PLoS One 2017; 12:e0180251.

24. Punnoose EA, Atwal SK, Spoerke JM, et al. Molecular biomarker analyses using circulating tumor cells. PLoS One 2010; 5: e12517.

25. Wicha MS. Circulating tumor cells: not all detected cells are bad and not all bad cells are detected. J Clin Oncol 2011; 29: 1508-11.

26. Watanabe T, Okumura T, Hirano K,et al. Circulating tumor cells expressing cancer stem cell marker CD44 as a diagnostic biomarker in patients with gastric cancer. Oncol Lett 2017; 13: 281-8.

27. Zhang X, Hua R, Wang X, et al. Identification of stemlike cells and clinical significance of candidate stem cell markers in gastric cancer. Oncotarget 2016; 7: 9815-31.

28. Ibrahim HM, AbdElbary AM, Mohamed SY, et al. Prognostic value of cyclin D1 and CD44 expression in gastric adenocarcinoma. J Gastrointest Cancer 2019; 50: 370-9.

29. Senel F, Kökenek Unal TD, Karaman H, et al. Prognostic value of cancer stem cell markers CD44 and ALDH1/2 in gastric cancer cases. Asian Pac J Cancer Prev 2017; 18: 2527-31.

30. Park J, Kim SY, Kim HJ, et al. A reciprocal regulatory circuit between CD44 and FGFR2 via c-myc controls gastric cancer cell growth. Oncotarget 2016; 7: 28670-83.

31. Wei Z, Chen X, Chen J, et al. RASSF10 is epigenetically silenced and functions as a tumor suppressor in gastric cancer. Biochem Biophys Res Commun 2013; 432: 632-7.

32. Xu M, Gong A, Yang H, et al. Sonic hedgehog-glioma associated oncogene homolog 1 signaling enhances drug resistance in CD44(+)/Musashi-1(+) gastric cancer stem cells. Cancer Lett 2015; 369: 124-33.

33. Wei B, Sun X, Geng Z, et al. Isoproterenol regulates CD44 expression in gastric cancer cells through STAT3/ MicroRNA373 cascade. Biomaterials 2016; 105: 89-101.

34. Bates RC, Edwards NS, Burns GF. A CD44 survival pathway triggers chemoresistance via lyn kinase and phosphoinositide 3-kinase/Akt in colon carcinoma cells. Cancer Res 2001; 61: 5275-83.

35. Chiappini PBO, de Medeiros IUD, Lima LGC, et al. Prognostic implications of phosphatidylinositol 3-kinase/ AKT signaling pathway activation in gastric carcinomas. Arch Med Sci 2017; 13: 1262-8.

36. Adachi Y, Yoshimura M, Nishida K, et al. Acute phase dynamics of circulating tumor cells after paclitaxel and doxorubicin chemotherapy in breast cancer mouse models. Breast Cancer Res Treat 2018; 167: 439-50. 